\title{
BARATARIA: EL SABER DE LOS COMUNES
}

\author{
BARATARIA: COMMON WISDOM
}

José Carlos Fernández Ramos

Universidad Nacional de Educación a Distancia. Madrid/España

jcfernandezr@invi.uned.es

Recibido/Received: 19/12/2017

Modificado/Modified: 12/06/2018

Aceptado/Accepted: 10/09/2018

\section{RESUMEN}

El famoso episodio de El Quijote que recoge el paso de Sancho Panza por el gobierno de la Ínsula de Barataria nos ofrece la posibilidad y el pretexto idóneo para sumergirnos en dos cuestiones cardinales cuyo esclarecimiento nos permitirá lograr una comprensión de mayor alcance y profundidad del clásico cervantino y de la sociedad estamental en que se contextualiza la narración. La primera, sería la inopinada y sorprendente irrupción del médico Pedro Recio a la vera del gobernador manchego, en consonancia con el nuevo estatus que los profesionales de la medicina habían escalado, hasta situarse en puestos aledaños del poder en España. La segunda, destinada a percibir la estratificación social que nos explica y ubica en el contexto social adecuado para comprender tanto las palabras como las obras del gobernador manchego en su efímera regencia de la ínsula.

\section{PALABRAS CLAVE}

Ínsula; gobernador; médico; saber popular; conocimiento científico.

\section{SUMARIO}

1. Introducción y Objetivos. 2. Metodología y Marco Teórico. 3. Desarrollo. 3.1. Reconsejo de Don Quijote. 3.2. Estatuto de Limpieza de Sangre. 3.3. Sancho "el justiciero". 3.4. Némesis médica. 3.5. Ronda de noche. 3.6. Desenlace. 4. Conclusiones. Bibliografía.

\begin{abstract}
The famous episode of Don Quixote that covers the account of Sancho Panza's government in the island of Barataria, gives us the opportunity and the ideal pretext to immerse ourselves into the very heart of two pivotal questions whose elucidation will enable us to widely understand the scope and depth of the Cervantine classic and the stratified society in which the narration is contextualized. The first one will be the unexpected and surprising irruption of the doctor, Pedro Recio, next to the Manchegan governor in accordance with the new status that medical practitioners have reached, close to powerful positions in Spain. The second one, aimed to perceive the social stratification that explains and places us within the right context to understand both the spoken words and the governor's work in his ephemeral regency in the island.
\end{abstract}

\section{KEYWORDS}

Island; governor; doctor; popular wisdom; scientific knowledge. 


\section{CONTENTS}

1. Introduction and Objectives. 2. Research Methodology and Theoretical Framework. 3. Development.

4. Conclusions. References.

\section{INTRODUCCIÓN Y OBJETIVOS}

Este ensayo pretende mostrar un capítulo de la secular pugna de los saberes populares, que generalmente se entienden como sentido común, aunque realmente son conocimientos obtenidos por el método de prueba y error, constituyendo la base experiencial de los pueblos transmitida por vía oral de generación en generación, frente al racionalismo cartesiano fundamentado en el método científico, en la genial novela de Miguel de Cervantes, y que a la postre viene a malograr el pseudogobierno de Sancho Panza en su, en principio, anhelada insula de Barataria. Por otra parte, trataremos de explicar cómo y porqué se origina y manifiesta una insólita y germinal intrusión iatrogénica en la literatura española, jugando un papel crucial en el desarrollo y desenlace del episodio del gobierno sanchesco.

\section{METODOLOGÍA Y MARCO TEÓRICO}

Metodológicamente nos apoyaremos en el análisis sociometafórico de los imaginarios sociales, cuyos fundamentos y modo de aplicación han alcanzado un necesario y suficiente grado de desarrollo, que continúa madurando día a día frutos más selectos, crecidos a la sombra de un, cada vez más nutrido, grupo de filósofos y científicos sociales en general (Lakoff y Johnson, 1981; Turner, 1996; Kitay, 1987; Kofman, 1983; González García, 1998, 2006; Lizcano, 1999, 2006; Fernández Ramos, 2015, 2017).

Como es conocido, la irrupción de la Modernidad y su posterior consagración ilustrada se caracterizó, entre otras cosas, por el cuestionamiento sistemático de los saberes populares y su minuciosa y premeditada demolición. El saber de los comunes había dominado desde la más remota antigüedad el ámbito que las nuevas ciencias naturales y sociales pretendían ocupar. Desde entonces se libra una guerra soterrada, en ocasiones cruelmente explícita, entre los conocimientos populares y las ciencias que surgieron a lo largo del Renacimiento, cuyo saldo, aun siendo indiscutiblemente favorable a la razón tecno-científica, jamás ha conseguido extinguir por completo la llama de la cultura popular.

El gobierno insulano de Sancho forma parte de una chanza muy elaborada que los duques, su mayordomo y criados, urden para risa y solaz de sus cortesanos. Buena parte de la crítica identifica a estos misteriosos personajes con los históricos duques de Luna y Villahermosa, pero no se conoce con certeza su identidad y la cuestión sigue abierta. No extraña esta ocultación cervantina de la identidad de los nobles, cuando se comprende la naturaleza cruel y mezquina de la burla que organizan en torno a los ilustres caminantes.

Pero antes de adentrarnos en la investigación, habremos de tomar en consideración una cuestión previa trascendental que hace ostensible el ingenio cervantino; los hechos aquí narrados ocurren cuando ya se había publicado, con notable éxito, la primera parte del libro. Los protagonistas, y en esto reside la genialidad del autor, son conscientes y se muestran orgullosos de su fama; sus anfitriones los reconocen como personajes de la famosa novela, creando unas conexiones y correspondencias entre ficción y realidad de enormes implicaciones filosóficas. Ambigüedades y equivalencias afines a las que presenta el cuadro 
de "Las Meninas" de Velázquez (1656), tan exquisitamente analizadas en Las Palabras y las Cosas por Michel Foucault (1984), y que aun no siendo el momento de tratar aquí, conviene no olvidar.

\section{DESARROLLO}

\subsection{Reconsejo de Don Quijote}

El episodio transcurre inmediatamente después de la aventura con el caballo Clavileño, en la que Don Quijote busca desafiar en singular combate al gigante Malambruno, quien envía una montura de madera con poderes mágicos que los hará volar por los aires hasta su morada. Tendrían, les advierte el duque, que llevar los ojos vendados para no despeñarse por los vértigos a las alturas de los abismos que surcarán. El caballero manchego cree a pie juntillas en los poderes sobrenaturales de la cabalgadura mecánica —en la Caballería eran corrientes esta clase de prodigios-, viniendo como vienen avalados por las palabras de sus nobles anfitriones y corroborados por testigos y criados. Más pragmático, Sancho sólo se convence de la realidad de la magia al sentir sobre su rostro y ropajes los vientos que los bromistas les arrojan con unos enormes fuelles, efecto inequívoco, cree él, del aéreo y veloz viaje.

La farsa insulana comienza con una exhortación del duque a Sancho para que se "adeliñase y compusiese para ir a ser gobernador, que ya sus insulanos le estaban esperando como agua de mayo", y añade una promesa, que disfrutará del gobierno pues "es dulcísima cosa el mandar y ser obedecido", a lo que Sancho replica desde su limitada experiencia que tal cosa "yo imagino, aunque sea a un hato de ganado", exhibiendo una perspicacia psicológica natural al percibir el deleite que en algunas personas provoca la imposición de la propia voluntad sobre los demás.

El duque comunica a Sancho que deberá ir "vestido parte de letrado y parte de capitán, porque en la ínsula que os doy tanto son menester las armas como las letras; y las letras como las armas." Sancho, que se sabe desprovisto de letras, dice bastarse con la memoria de Christus "para ser buen gobernador", aunque en cuestión de armas "manejaré las que me dieren, hasta caer". Los duques y el resto de los urdidores de la trama burlesca dudan entre el escarnio y la admiración ante las comedidas y juiciosas palabras de quien consideran un simple patán de campo.

Don Quijote, avisado de la inminente partida del nuevo gobernador hacia su ínsula, apresura su reconsejo, improvisando unas prudenciales pautas mínimas de buen gobierno tan ajustadas a la ocasión como adecuadas a las circunstancias:

Primeramente, joh hijo!, has de temer a Dios; porque en el temerle está la sabiduría, y siendo sabio no podrás errar en nada. Lo segundo, has de poner los ojos en quien eres, procurando conocerte a ti mismo, que es el más dificil conocimiento que pueda imaginarse. Del conocerte saldrá el no hincharte como la rana que quiso igualarse con el buey (Cervantes, 2008: 868).

Dicho lo cual prosigue su discurso el caballero andante poniendo en entredicho una de las instituciones más controvertidas, trascendentales e influyentes del momento histórico, la pureza de sangre.

\subsection{Estatuto de Limpieza de Sangre}

A pesar de lo chocantes que debieron sonar sus palabras, contrarias a la corriente 
dominante de su tiempo, Don Quijote sostiene con valentía: "la sangre se hereda, y la virtud se aquista, y la virtud vale por sí sola lo que la sangre no vale". El primer Estatuto de Limpieza de Sangre apareció en Toledo en 1449 a raíz de una revuelta de los cristianos viejos contra un impuesto de un millón de maravedíes que el condestable don Álvaro de Luna, favorito del rey, exigió a la ciudad para sufragar la guerra contra Aragón, a sugerencia del comerciante converso Alonso Cota. El alcalde mayor de la ciudad y copero del rey, Pedro Sarmiento se puso al frente de los rebeldes y forzó la retirada de las tropas reales. Ante el pueblo reunido el 5 de junio de 1449 proclamó la Sentencia Estatuto que permitía expulsar a todos los judíos conversos de los puestos más relevantes de Toledo como: concejales, jueces, alcalde y especialmente las escribanías y notarías. En principio, este estatuto recibió el rechazo de la iglesia y la corona, y obtuvo una inmediata réplica, el 24 de septiembre de ese mismo año, en la bula Humani Generis del papa Nicolás V, quien lo desautorizó de forma tajante. A pesar de ello, su práctica se fue imponiendo progresivamente primero en la Iglesia, luego en las órdenes militares y monásticas y, por último, en toda una serie de empleos oficiales y gremiales en los que se vetaba a los que no pudieran demostrar que su linaje estaba compuesto únicamente por cristianos viejos, hasta en siete generaciones anteriores. Al final, tanto el Rey como el Vaticano dictaron normas respaldando su aplicación. No se trataba tanto de un concepto racista, como ideológico, ya que no solo perseguía preservar una raza pura, sino conservar la integridad y pureza del dogma católico. Aunque también escondía un substrato de lucha de clases pues los cristianos nuevos - judíos y musulmanes conversos - representaban, frente a la mayoría campesina, a la pequeña burguesía urbana e industrial que acaparaba los puestos de plateros, tundidores, tejedores, zapateros, impresores, curtidores, sederos y otros empleos típicamente urbanos como abogados, administradores, escribanos, médicos, boticarios, sastres, libreros y, sobretodo, mercaderes.

La exigencia de limpieza de sangre para ocupar ciertos cargos oficiales, reservados solo para hidalgos, desató una obsesiva preocupación por la genealogía por parte de los nobles españoles del Siglo de Oro. Para demostrar dicha limpieza surgieron una legión de linajistas que se encargaron de elaborar falsas genealogías que demostraran la condición de "cristiano viejo" y la ausencia de impurezas en la sangre de cualquiera que fuese capaz de pagar sus abultados honorarios. En Sevilla floreció una verdadera mafia de estos falsos linajistas que se dedicó durante buena parte de la centuria a extorsionar a todo aquel ricazo o pretendiente a cargo público que no usara y costeara generosamente sus servicios.

A la hora de juzgar, prosigue el Hidalgo: "Procura descubrir la verdad por entre las promesas y dádivas del rico como por entre los sollozos e importunidades del pobre", y si has de juzgar a un enemigo "aparta la mientes de tu injuria y ponlos en la verdad del caso. No te ciegue la pasión propia en la causa ajena.” Los demás consejos que le procuró se centraban en la propia persona de Sancho y versaban sobre el arreglo en el vestir, la frugalidad en el comer y dormir, y el recato en el folgar, por respeto a sí mismo y a su esposa.

\subsection{Sancho "el justiciero"}

Oídos y recogidos por escrito el reconsejo de su señor, el escudero emprende camino hacia su ínsula. Al llegar es recibido por un regimiento a las puertas de la villa donde se había congregado todo el pueblo que con mucha pompa y entre vítores lo conducen a la Iglesia Mayor a dar gracias a Dios para, después de unas ridículas ceremonias, entregarle las llaves del lugar, admitiéndolo "por perpetuo gobernador de la ínsula Barataria." Del palio trasladan a Sancho al sitial del juzgado para que considerase y respondiera, según antigua costumbre, a unas intrincadas y dificultosas cuestiones como todo "el que viene a tomar posesión desta famosa ínsula", de modo que el pueblo pudiera tomar "el pulso del ingenio de su nuevo 
gobernador".

Allí sentado con pose de juez, Sancho recibe en la sala a dos personajes, un sastre y su descontento cliente; éste relata que llevó al artesano un trozo de paño para hacerse una caperuza, pero sabiendo que algo de tela sobraría preguntó si ¿no habría para dos? y el sastre le dijo que podría; o ¿para tres?, a lo que también asintió el artesano, y así continuó hasta cinco. El sastre sabía que podría confeccionarlas, pero tendría que hacerlas más y más pequeñas conforme aumentaba su número, aunque, ladinamente, guardó tal reflexión para sí. Al entregar el trabajo al cliente, el artesano le presentó las cinco caperuzas que sólo servirían para cubrir la yema de los dedos de la mano, con lo que el labrador se ofendió, acudiendo al juicio del nuevo gobernador para resolver la cuestión. Sancho consideró y solventó el problema de un plumazo:

Paréceme que en este pleito no ha de haber largas dilaciones, sino juzgar luego a juicio de buen varón; y así, yo doy por sentencia que el sastre pierda las hechuras, y el labrador el paño, y que las caperuzas se lleven a los presos de la cárcel, y no haya más (Cervantes, 2008: 890).

Sancho percibe la nimiedad del pleito y advierte tanto la tacañería del labrador exigiendo más y más caperuzas, como la trampa del sastre al ocultar que mientras crecía el número de caperuzas encogía su tamaño. Así condena a ambos, al cliente por cicatero, al sastre por embaucador.

El segundo juicio que tuvo que dirimir Sancho, mucho más peliagudo, enfrenta a dos ancianos por el préstamo de diez escudos de oro que uno hizo al otro. Uno de ellos, apoyado en una cañaheja que le servía de báculo, dice que ya devolvió la deuda y el otro que jamás hubo tal cosa, pero que, si "vuestra merced le tomase juramento, y si jurare que me los ha devuelto, yo se los perdono". En aquel tiempo un juramento ante Dios en presencia de la autoridad civil no era asunto de broma, el perjuro podría enfrentarse a la hoguera, de ahí que el demandante aceptase como suficiente tal método probatorio. El deudor accede a realizar el juramento y para ello pide al prestamista que le sujete el báculo, mientras, con la mano sobre la cruz, jura ante todos haberle devuelto el oro. El prestador queda así satisfecho, aunque contrariado pues cree haber olvidado "el cómo y cuándo se los había devuelto". Los litigantes se retiraban ya, mientras Sancho quedó absorto por un instante, pero al cabo mandó que llamasen al anciano del báculo, que raudo se alejaba con ayuda de su bastón. Retornó el viejo y el gobernador le solicitó que le entregara el báculo, Sancho lo recogió, y dándolo al otro dijo: "Andad con Dios, que ya vais pagado". El anciano suspenso e indignado preguntó si acaso aquella muleta de caña valía los diez escudos de oro que prestara, a lo que el juez manchego replicó que en ese instante se vería si él tenía o no "caletre para gobernar todo un reino":

$Y$ mando allí, delante de todos, se rompiese y abriese la caña. Hizose así, y en el corazón della hallaron diez escudos en oro; quedaron todos admirados, y tuvieron a su gobernador por un nuevo Salomón (Cervantes, 2008: 891).

Interrogado por los presentes sobre cómo había colegido que en aquella cañaheja se hallaba el oro reclamado, Sancho indicó que al ver jurar al viejo que real y verdaderamente lo había devuelto, y estando al tanto del riesgo que corría el perjuro, dedujo que en ella iría escondido el oro, así no habría afrenta a Dios ni a la autoridad, y al final, solicitando que le regresaran su bastón, los diez escudos volverían con él. Tal demostración de cordura y buen sentido admiró a todos y más a quienes conocían que solo era una parodia para reír a costa del campesino. Así continuó juzgando entuertos, derrochando sentido común y buen juicio, 
proporcionando una severa lección ética que sus burladores no olvidarían, ya que los duques habían ordenado a un escribano que se apuntara y se les informase de todo cuanto hiciera y dijera el escudero.

\subsection{Némesis médica}

Del Juzgado trasladaron a Sancho a un suntuoso Palacio, residencia oficial del gobernador, y al entrar en una gran sala, donde lucía una "real y limpísima mesa puesta", sonaron las chirimías y "salieron cuatro pajes a darle aguamanos". Descubrieron la mesa y apareció repleta de bandejas desbordantes de fruta y suculentos platos con diversos manjares que pusieron ante él, pero "apenas hubo comido un bocado" cuando un personaje que se había situado a su vera ordenó que se los retiraran, diciendo:

Yo, señor, soy médico, y estoy asalariado en esta ínsula para serlo de los gobernadores della, y miro por su salud mucho más que por la mía, estudiando de noche y de dia, y tanteando la complexión del gobernador, para acertar a curarle cuando cayere enfermo; y lo principal que hago es asistir a sus comidas y cenas, y a dejarle comer lo que me parece le conviene, y a quitarle lo que imagino que le ha de hacer daño y ser nocivo al estómago; y así, mandé quitar el plato de la fruta, por ser demasiadamente húmeda, y el plato del otro manjar también le mandé quitar, por ser demasiadamente caliente y tener muchas especies, que acrecientan la sed, y el que mucho bebe, mata y consume el húmedo radical, donde consiste la vida (Cervantes, 2008: 900).

La autoridad científica del médico basta para que Sancho acepte, aunque de mala gana, su consejo y ordena que le acerquen un plato de perdices bien sazonadas, que seguro no le causarían ningún mal, a lo que el galeno replica que "ésas no comerá el señor gobernador en tanto que yo tuviere vida”. Pero ¿por qué no?, objetó Sancho:

Porque nuestro maestro Hipócrates, norte y luz de la medicina, en un aforismo suyo dice: Omnis saturatio mala, perdices autem pessima. Quiere decir: "Toda hartazga es mala; pero la de perdices, malísima» (Cervantes, 2008: 901).

Sancho, por lo tanto, ruega que de la opulenta mesa le acercasen aquello que comer sin daño pudiera, como unos conejos guisados o la ternera asada y en adobo, pero a cada plato nombrado surge una nueva negativa del médico. Al final, exasperado por tanta censura, solicita una olla podrida que atisba en un extremo de la mesa que, como ya la había comido en otras ocasiones sin causarle ningún mal, pensaba no recibiría reproche alguno, pero Recio, implacable, alegó exhortativo:

Absit! [...] Vaya lejos de nosotros tan mal pensamiento: no hay cosa en el mundo de peor mantenimiento que una olla podrida. Allá las ollas podridas para los canónigos o para los retores de colegios o para las bodas labradorescas, y déjenos libres mesas de los gobernadores, donde ha de asistir todo primor y toda atildadura; [...] Mas lo que yo sé que ha de comer el gobernador ahora para conservar su salud y corroborarla, es un ciento de canutillos de suplicaciones y unas tajadicas sutiles de carne de membrillo, que le asienten el estómago y le ayuden a la digestión (Cervantes, 2008: 901-902).

Sancho, colérico, ya no puede más con el hambre que el médico le impide saciar y estalla: "quíteseme luego delante, si no, voto al sol que tome un garrote y que a garrotazos, comenzando por él, no me ha de quedar médico en toda la ínsula”. Aunque parezca una 
causa general contra la medicina y sus practicantes, en este pasaje el escudero no juzga y condena a su médico por médico, sino por ignorante y malintencionado:

Que a los médicos sabios, prudentes y discretos los pondré sobre mi cabeza y los honraré como a personas divinas [...] que se me vaya, Pedro Recio, de aquí; si no, tomaré la silla donde estoy sentado y se la estrellaré en la cabeza [...] que yo me descargaré con decir que hice servicio a Dios en matar a un mal médico, verdugo de la república (Cervantes, 2008: 902).

La inopinada aparición del galeno en el relato está justificada por las circunstancias históricas. A pesar del denostado papel que la literatura áurea le otorgaba, en ese tiempo el oficio hipocrático gozaba ya de un notable prestigio en el imaginario popular. Los médicos de entonces no sólo atendían a las curaciones y a los cuidados que sus practicantes dispensaban al cuerpo humano, sino que extendían sus atenciones al cuerpo político.

Heredera de la metáfora del cuerpo místico, que concebía a la comunidad cristiana como un cuerpo cuya cabeza es Cristo, en la baja Edad Media se había forjado y tomado carta de naturaleza en el imaginario social una metáfora equivalente que veía la república como un cuerpo humano. En el barroco, la fuerza de la metáfora orgánica aplicada a comprender la república como un cuerpo fue tal que el desprestigio de los médicos, hasta entonces vituperados por la literatura, comenzó a cambiar de signo. Se suponía que quién mejor conociera y supiera tratar y sanar eficazmente los cuerpos humanos heridos o enfermos, del mismo modo, sabría remediar los males que aquejaran al cuerpo político de la república. De ahí la elevada posición social que algunos practicantes de la medicina alcanzaron como cargos públicos, convirtiéndose en los consejeros ideales del soberano barroco en la Europa católica.

Esta perspectiva iatrogénica de la política trajo consigo la proliferación de numerosos tratados políticos escritos por médicos. Entre otros muchos, podemos citar a los médicosconsejeros y tratadistas del Renacimiento: Miguel Sabuco, Francisco Sánchez, Francisco Vallés, Constantino Ponce, Juan Villalobos, Miguel Servet, Andrés Laguna o Luis Mercado. Y en el Barroco a: Sancho Moncada, Miguel Martínez de Leyva, Victoriano Zaragozano y Zapater, Cristóbal Pérez de Herrera, González Cellórigo, Pedro Mercado, etc. De ahí el acierto cervantino al incluir en la narración la presencia de Don Pedro Recio ladeando al gobernador.

Un ejemplo paradigmático de esa irrupción de los profesionales de la medicina en la ciencia política, estrictamente contemporáneo de Cervantes, lo constituye el caso del catalán Jerónimo Merola, nacido en Balaguer, con estudios de filosofía y medicina en la Universidad de Barcelona que, en 1587, publicó un texto con el explícito título: República original sacada del cuerpo humano. En el prólogo Merola justifica la intrusión de la medicina en la política acomodando un dicho clásico a sus propósitos: "el cuerpo [no el hombre] es la medida de todas las cosas" y, en consecuencia, añade, el cuerpo humano está en la base de la organización de la vida política, ya que "existe una correspondencia entre nuestro cuerpo y el de la república". Esa correspondencia está mediatizada por la metáfora que ve la república desde la perspectiva del cuerpo humano.

Al juzgar los males que pueden aquejar al cuerpo físico, Merola opina que la modificación de alguno de los órganos o la alteración de sus actividades conduce a una perturbación que repercute sobre todo el organismo y ocasiona un desequilibrio global que puede arrastrar a la muerte, lo mismo que podría sucederle a una república. El cuerpo humano da la clave porque: "Siguiendo en todo la cifra de nuestro cuerpo, cuyo vivo retrato es nuestra república" se pueden atajar sus males. Completa así un círculo metafórico ya que si, como dice, el 
cuerpo es vivo retrato de la república, a ésta la acaba mirando como a un cuerpo humano. Así expresa su admiración sobre el particular:

Cuando más me voy metiendo en las cosas de nuestro cuerpo, y por sus partes voy midiendo las de la República, más a las veras me voy maravillando de ver lo mucho que se parecen (Merola, 1587: 47).

En la anatomía humana, que Merola conocía por su profesión, existen tres órganos considerados fundamentales: el cerebro, asiento del juicio y de los movimientos voluntarios e involuntarios; el corazón, sede simbólica de la voluntad, que suministra vida al cuerpo todo, regándolo con la sangre nutritiva que se elabora en el tercero de los centros vitales, el hígado. El médico catalán advierte una correspondencia con los que considera centros vitales de la república, que legitima la metáfora: el cerebro corresponde al Estado Eclesiástico, el corazón al Estado Militar y el hígado al Tercer Estado, siguiendo la conocida analogía de la versión platónica de la misma metáfora.

Sin embargo, el rey, a quien otros autores equiparan a la cabeza, corazón o alma de la república, carece de una correspondencia precisa en el sistema de Merola. Sólo el poder de Dios hace posible, según él, la existencia del rey y por ello no puede ser considerado como los demás hombres y así le atribuye cualidades panteístas cuasi divinas: "el rey se encuentra pues en todas partes y en ninguna" y, en todo caso, se encuentra más allá del cuerpo que forman sus súbditos. El médico no encuentra aplicable la metáfora corporal al monarca, porque en España el rey está legitimado como elegido y sancionado por Dios y en cuanto tal está por encima y más allá de todo lo corporal-material.

Deja claro Merola, sin embargo, que el monarca — en tanto que hombre natural- no queda a resguardo de la muerte pues su cuerpo físico está dominado por su naturaleza mortal, pero la investidura divina le insufla cierta cualidad que obliga al sometimiento de toda la república a su voluntad soberana.

La metáfora médica convierte el cuerpo político, aquejado por los males de la época, en paciente al que tratar con remedios clínicos equivalentes a los usados para las enfermedades del cuerpo físico. Las enfermedades serían la ruina política, económica y militar, en que los arbitristas ven sumida a Castilla, justificando un movimiento generalizado de autocrítica e introspección que dio lugar a un nuevo género de análisis político: la llamada literatura de crisis. Marcado por la metáfora del cuerpo y su ampliación iatrogénica, el discurso arbitrista asumió la tarea de diagnosticar las dolencias que sufría el reino y de recetar los posibles remedios a los males del quejumbroso cuerpo político castellano.

En el siglo XVII la metáfora corporal está completamente asumida por los escritores, no sólo políticos, como Gracián o Quevedo. Andrés Mendo, por ejemplo, en 1657 en su Príncipe perfecto y Ministros ajustados (Santos Herrán y Santos López, 2008: 240-253) ya no usa comparación alguna, sino una identidad metafórica total entre sujeto y término:

Necesita el príncipe de muchos ojos, oídos, y manos, y lo son sus consejeros, y ministros [...] Y no bastando dos ojos, y dos oídos, para verlo, y oírlo todo, ni dos manos para la ejecución, han de llenar este ministerio los magistrados, que ayudan a llevar el peso del gobierno [...] Tantos ojos, oídos y manos se añade un rey, cuantos ministros prudentes y celosos tiene. Por ellos ve, oye y obra (Documento LXVII).

Utilizando la metáfora corporal Mendo trata de ajustar cada circunstancia real de los órganos del príncipe a su equivalente metafórico en el cuerpo político con la mayor naturalidad:

Nadie puede gozar de tan perspicaz vista, que registre las mayores distancias, 
porque es limitada la esfera de los ojos. Dos manos solas no tienen fuerza para multiplicadas obras [...] Y para el gobierno sirven de ojos, manos y alivio los ministros (Documento LVII).

La transposición de los campos semánticos del cuerpo anatómico al cuerpo político abandona parcialmente su carácter heurístico, extendiendo la aplicación del léxico médico al cuerpo político hasta casi desaparecer cualquier referente, quedando solamente la representación como auto-referente. En consecuencia, la metáfora del cuerpo político poco a poco se banaliza, personificando dramáticamente al reino como el doliente, el afligido o el enfermo. En su versión más desaforada los escritos políticos de los arbitristas ofrecen una visión del imperio acorde con la imaginería barroca de la Pasión como cuerpo martirizado y ecce homo político. Cuerpo flagelado y torturado por una cabeza regente de apetito voraz que extrae la sangre de sus miembros hasta la extenuación, cuerpo exangüe por el sobresfuerzo tributario y militar que la corona le exige. Se citan asiduamente como males del reino las bancarrotas de las cuentas públicas, las devaluaciones periódicas de la moneda para diferir o anular los pagos de la deuda contraídas con la burguesía y la banca extranjera, así como la proliferación de foráneos en la Corte, a los que se considera humores nocivos y venenos que infectan y emponzoñan el cuerpo político hispano. Humores que hay que purgar para el logro de la salud pública. El Reino, se dice, está contagiado por una enfermedad mortal, sufre la infección de la peste traída por la banca internacional en atención a las ambiciones imperiales del soberano.

El paroxismo de esta representación trágica del cuerpo político lacerado y desmayado se alcanza con la imagen de la hemorragia constante de las heridas del reino, la sangría continuada de la población por las reiteradas levas y los impuestos abusivos para financiarlas. Así un arbitrio de Céspedes y Meneses resume melodramáticamente la situación, sentenciando: "Sangrías continuadas sobre flaqueza son mortales" (Redondo, 1992: 67).

En síntesis, los escritores políticos hispanos lograron establecer una metáfora corporal, aplicada a comprender la república comparándola con el cuerpo humano. Es un cuerpo orgánico sujeto a las mismas exigencias y restricciones medioambientales que padecería cualquier ser vivo. La república es, por tanto, un cuerpo cuya salud depende, en el interior, de un equilibrio dinámico de humores y, en el exterior, del necesario intercambio metabólico con el medio. En el orden interno el desequilibrio humoral de la república trae consigo la enfermedad que podría llegar a acarrear su muerte. En el externo puede sufrir alguna agresión de su entorno, resultar herida por un ataque extranjero, incluso perecer al ser incorporada por conquista a otro Estado.

En marcado contraste con la metáfora hispana del cuerpo político, en la Europa anglosajona y protestante, se institucionalizó otra metáfora diferente para entender el Estado: la que lo concebía como un mecanismo de relojería. La nueva concepción de lo corporal, que instituye el Renacimiento, se culmina en el racionalismo de Hobbes con la inclusión del mecanicismo que concibe al ser humano como autómata. El hombre fue pensado entonces como una especie de maquinaria similar a los autómatas que ofrecían sus espectáculos en ferias y villas. Con la eclosión del primer maquinismo, fruto del avance de las ciencias modernas, comenzó su andadura otra metáfora mecanicista que veía al mismo ser humano como una maquinaria:

¿Por qué no podríamos decir que todos los autómatas (artefactos movidos por sí mismos mediante muelles y ruedas, como un reloj) tienen vida artificial? Pues ¿qué es el corazón sino un muelle? ¿Y qué son los nervios sino otras tantas cuerdas? ¿Y qué son las articulaciones sino otras tantas ruedas, dando movimiento al cuerpo en 
su conjunto tal como el artífice proyectó? (Hobbes, 2003: 39).

Las diferencias respecto a la concepción de lo corporal se materializaron en la conformación de dos ideas divergentes del cuerpo político, una sustentada por la metáfora orgánica del cuerpo y la otra apoyada en la mecánica: el cuerpo racionalista fue pensado como autómata, el hispano como organismo vivo. El racionalista está formado por piezas: cuerdas, poleas, engranajes y ruedas ensambladas. El hispano por miembros, órganos y humores. Uno funciona, el otro vive. El primero actúa con el automatismo y la impersonalidad de la máquina realizando la función para la que fue construida, el segundo crece y se desarrolla adaptándose al medio ambiente mediante el intercambio metabólico. El racionalista se avería, el hispano enferma. El primero se repara, el segundo se cura. Para su mantenimiento y reparación el autómata necesita mecánicos —así se llamó a los científicos de la Royal Society que aconsejaban al Rey de Inglaterra-, por el contrario, el cuidado y cura del organismo necesita médicos - por eso los practicantes de la medicina barroca gozaron de un enorme predicamento social.

Sin embargo, en ambas interpretaciones el uso e interiorización de estas metáforas naturaliza una idea: la necesidad social de un orden jerárquico y la existencia de una autoridad superior — del tipo que fuere - como algo indispensable, pues tolerar su ausencia equivaldría a admitir la viabilidad de un cuerpo decapitado, algo inimaginable, que no puede existir, muriendo todo el cuerpo irremediablemente.

Por tanto, en las dos versiones de la metáfora que nos ocupan, se trata de cuerpos estrictamente jerarquizados, que presuponen un orden escalonado de importancia de sus miembros en función de la mayor o menor relevancia para la vida del órgano o pieza de que se trate (Keller, 1991, 29 y ss.). Asumiendo estas metáforas, cualquier categorización social queda automáticamente legitimada. Y se corta de raíz — por antinatural— cualquier posible intento de rebelión, ya que a nadie cabe imaginar que una pieza de la máquina o un órgano del cuerpo desobedezcan a su cabeza. Tal conducta sediciosa sería considerada y tratada como peligrosa enfermedad — en la versión orgánica—, siendo medicalizada con remedios sanitarios, que podrían llegar al extremo de la amputación. O bien, se presentaría como un desperfecto o avería — por la metáfora mecánica- a los que aplicar soluciones técnicas, reparación o sustitución de la pieza dañada. Se justifican y se da con ello carta de naturaleza a las acciones terapéuticas, punitivas o reparadoras que la cabeza pueda prescribir y aplicar a tales miembros enfermos o mecanismos averiados, legitimando así los sistemas penales en términos médicos o mecánicos.

Pero volvamos a Sancho, a quien dejamos vituperando a su médico por escatimarle el alimento, que recibe una carta en la que el duque le anuncia malhadadas nuevas sobre un grupo de personas disfrazadas que han irrumpido en su ínsula con intención de "quitaros la vida, porque se temen de vuestro ingenio", desatando la cadena de sucesos que culminarán el hartazgo de Sancho respecto al gobierno de su ínsula. No obstante su sorpresa, Sancho insiste:

Lo que agora se ha de hacer, y ha de ser luego, es meter en un calabozo al doctor Recio; porque si alguno me ha de matar ha de ser él, y de muerte adminicula y pésima, como es la de la hambre (Cervantes, 2008: 903).

Por fin el doctor Recio, amedrentado por el discurso de Sancho, se pliega a sus deseos prometiendo alimentarlo esa noche "aunque excediese todos los aforismos de Hipócrates". 


\subsection{Ronda de noche}

Dicho y hecho, Sancho por fin logró llenar el buche y saciar su apetito. Satisfecho, retoma sus obligaciones como gobernador acompañando a la guardia en su ronda nocturna:

$Y$ en siendo hora, vamos a rondar, que es mi intención limpiar esta ínsula de todo género de inmundicia y de gente vagabunda, holgazanes y mal entretenida. Porque quiero que sepáis, amigos, que la gente baldia y perezosa es en la república lo mismo que los zánganos en las colmenas, que se comen la miel que las trabajadoras abejas hacen. Pienso favorecer a los labradores, guardar sus preeminencias a los hidalgos, premiar a los virtuosos, y, sobre todo, tener respeto a la religión y a la honra de los religiosos (Cervantes, 2008: 919).

En esta somera declaración, el gobernador manchego utiliza con verdadero ingenio la metáfora de la colmena para juzgar el vagabundeo y despliega todo un programa de gobierno, con respeto a los privilegios estamentales tradicionales del clero y de la nobleza, pero premiando al industrioso labrador que sustenta los estómagos de todos.

La organización del Estado, tras la unificación propiciada por las nupcias de los que, poco después, serían llamados los Reyes Católicos, se basaba en la máxima de un rey para todos los reinos pero respetando las instituciones, leyes y fronteras de cada reino por separado y no perseguía el establecimiento de una monarquía absoluta como las que triunfarán en Europa poco después, sino, tal y como rezan los documentos oficiales de la época, el arraigo de una «monarquía preeminente» cuya autoridad prevaleciera sobre las demás instituciones, aunque respetuosa con las leyes propias de los reinos y el derecho consuetudinario de los súbditos (Payne, 1985: 12). Sin embargo, la llegada de los Augsburgo al trono suscitó diversos intentos uniformadores que desencadenaron una airada respuesta de los burgos ante la pérdida de su tradicional autonomía, desembocando en la rebelión de los Comuneros que se saldó con su derrota en Villalar (1521). El centralismo real tenía un objetivo básicamente recaudatorio: asegurarse los recursos humanos y económicos que se precisaban para satisfacer las ambiciones imperiales de Carlos I y de su hijo Felipe II, en especial respecto a Flandes, cuna de Carlos y símbolo del dominio hispano en Europa que supuso una auténtica sangría para la economía hispana.

Aun así, un siglo de intentos uniformadores después y cincuenta años antes de que Hobbes sentara las bases racionales del contractualismo moderno, el jurisconsulto, miembro del Consejo del Rey y Fiscal de Cataluña, Antonio Oliván, en su libro De Juri Fisci de 1600, seguía definiendo España como una federación de estados soberanos - avant la lettre - en la que cada estado mantenía sus propias leyes basadas en un contrato entre los súbditos y el rey (Oliván, LVIII, 15). Pese a la aparente modernidad de esa definición, la configuración del reino obedecía más a la persistencia de la tradicional sociedad estamental de la baja Edad Media que a un proceso institucional de racionalización, innovación y descentralización administrativa. La tenacidad de las instituciones tradicionales se percibe claramente en la estratificación de la sociedad barroca.

La sociedad estamental, que perdura en el tiempo en que se inserta la narración cervantina, clasificaba y encasillaba rígidamente a cada uno desde la cuna. En el escalón más alto se hallaban los hidalgos, cuya ideología era la ideología de la clase dominante, es decir, la ideología oficial que servía de modelo e intentaba imponerse al conjunto de la sociedad. Sus principales inquietudes no giraban en torno al conocimiento o la industria, sino alrededor de los conceptos caballerescos del honor y de la limpieza de sangre. La capa y la espada venían siendo sus signos de distinción a la vez que marca de hidalguía. Pero en el siglo XVII "todos 
los hombres, desde el primero hasta el último, se visten como caballeros, siempre con capa y espada", escribía sorprendido Edmund Verlney, miembro del séquito del Príncipe Carlos de Inglaterra, quien visitó de incógnito Madrid en 1623 con vistas a su posible casamiento con la Infanta doña María (Shaw, 1981: 216).

Entre los hidalgos los hubo inmensamente ricos con títulos nobiliarios logrados por algún glorioso antepasado en la batalla o en el servicio a la Corona; propietarios de grandes territorios, con multitud de sirvientes y esclavos a su cargo, a veces con numerosos pueblos enclavados en sus señoríos de los que extraían diezmos y mano de obra barata. Aquí podemos situar el estrato social del que procedían los duques bromistas. A la cabeza de ellos se encontraban los Grandes de España, con derecho a no descubrirse ante el rey, quien les dispensaba el tratamiento de "primos". Aunque también los había "pobres de solemnidad", cuyo único patrimonio consistía en el título heredado de caducos esplendores familiares. En este menesteroso grupo cabe incluir al Ingenioso Hidalgo.

Junto al clero, los hidalgos estaban exentos de pagar impuestos directos. Tampoco podían ser presos por el impago de deudas, ni ser sometidos a torturas, salvo casos excepcionales. Su noble condición hacía que en caso de encarcelamiento conservaran ciertos privilegios: se los eximía de las condenas a galeras o a ser azotados. Si incurrían en responsabilidades capitales, su muerte se producía por decapitación y no por ahorcamiento como los siervos. El régimen penal de los hidalgos en general era mucho más liviano; un homicidio podía acarrearles solamente una multa o el destierro, si la víctima era un igual, mientras que los miembros del tercer estado podían ser ejecutados por un simple hurto. En Castilla, a finales del XVI, se contabilizan 133 mil familias hidalgas. Todos los vizcaínos lo eran por ley ya que en el Fuero Nuevo de Vizcaya de 1526 se reconoció la hidalguía universal a todos sus naturales, por el apoyo prestado al ejército real frente a las Comunidades.

En el siguiente escalón se situaba la burguesía urbana, abonada por la abundante entrada de oro y plata procedente de América, la cual favoreció la importación de onerosos productos foráneos de lujo y ostentación procedentes de Italia y Francia, principalmente, que enriqueció a una parte del comercio urbano, pero empobreció a los artesanos locales. Los nuevos ricos del comercio suntuario, logrado el éxito económico, abandonaban inmediatamente la actividad y compraban juros — primera versión de la deuda pública en el reino de Castilla-, lo cual les permitía alcanzar el ideal cortesano de vivir de las rentas y codearse con la nobleza de sangre (Ubieto et al., 1991: 392).

El rápido éxito económico de unos — principalmente judíos y musulmanes conversossupuso la ruina de los oficios tradicionales que sufrieron un importante retroceso en este periodo. Esto provocaría la respuesta airada de los gremios con la intención de impedir la comercialización de productos extranjeros. Con fines proteccionistas se extremó el monopolio de sus mercados naturales y se establecieron nuevas reglamentaciones que impidiesen o frenaran durante lustros, el paso a maestros — con derecho a abrir su propio negocio- de los oficiales más cualificados. Escoltando a esta incipiente burguesía, se encuentran los primeros profesionales liberales, como el médico don Pedro Recio, atormentador de Sancho, quienes, junto a abogados, notarios y otros cargos burocráticos del Estado, formaban un grupo intermedio entre los burgueses ricos y los maestros, oficiales y aprendices en los diversos oficios artesanales de las urbes barrocas.

Entre los hombres libres, los campesinos fueron el grupo más desfavorecido, por explotado, de la sociedad barroca. Todas las crónicas de la época los sitúan en el escalón social más bajo. La mejor y mayor parte de las tierras de cultivo estaban en manos del clero o de la nobleza, los cuales recibían altas rentas a cambio de permitir su cultivo por parte de los 
campesinos lugareños. Generalmente, las cosechas se dividían en tres partes, dos de las cuales iban a parar a manos de la Iglesia o del terrateniente propietario, siendo un tercio para el campesino. Con lo que les restaba los agricultores ni siquiera podían satisfacer las necesidades mínimas de sus familias, no más que una elemental economía subsistencia. Sin embargo, al hablar del campesinado no podemos generalizar ya que no se trata de un grupo homogéneo. Distaba mucho la situación del pequeño propietario que cultivaba su propio minifundio, a la de un arrendatario en los latifundios del clero o de la nobleza, y mucho menos, si los comparamos con la situación del simple bracero que normalmente trabajaba de sol a sol por un techo donde guarecerse y comida para él y sus famélicas familias. Podemos deducir que nuestro gobernador manchego se sitúa en el escalón inferior de este estrato.

Los siervos ocupaban un ínfimo lugar en la consideración social y su número fue en aumento durante toda la centuria, pues la categoría de los nobles y burgueses ricos se medía por la cantidad de ellos que poseían. Su estatus dependía enteramente del de su amo, pero sus condiciones vitales nunca pasaron de la precariedad, de ahí el apelativo de paniaguados que la literatura áurea les dedicó, pues el pan y el agua eran la base principal de su sustento. La novela cervantina nos presenta múltiples ejemplos de ellos a lo largo de sus páginas.

Por último, existían innumerables esclavos en su mayoría procedentes de las conquistas de plazas árabes de Al Andalus. Desde la conquista de Granada muchos esclavos negros y moriscos quedaron en manos de los nobles o fueron vendidos a los burgueses con aspiraciones nobiliarias. Tras su reconquista, por ejemplo, la totalidad de las poblaciones de Valencia y Málaga fueron esclavizadas y vendidas como tales, al igual que ocurrió con todos los autóctonos de Canarias. Para agravar aún más la situación, muchos padres del tercer estado se vieron empujados por la miseria a vender como esclava a su progenie. La esclavitud suponía la privación absoluta de derechos — incluida la propia vida-, los cuales recaían sobre el dueño. A pesar de todo, se producían muchas liberaciones por dos vías: en pago de algún servicio especial al señor, en ocasiones, se premiaba al esclavo con la libertad, y por la vía del casamiento con el dueño viudo/a.

Por debajo de los esclavos incluso, quienes al menos tenían garantizado un mínimo sustento, se encontraban una multitud de marginados, indigentes y vagabundos entre los cuales abundaban minusválidos, mendigos y pícaros a quienes Sancho alude en su metáfora de los zánganos. Se estiman en 150 mil en toda la península a principios de siglo, solo en Madrid p. e., se censaron 3300 en 1637. Las malas cosechas, la carestía y las epidemias intensificaron la pobreza de los campesinos que engordaban día a día la legión de los excluidos y empujados a las grandes ciudades, principalmente Sevilla y Madrid. Esos grupos, en constante aumento, constituían, y así eran percibidos por el gobernador manchego, un peligro potencial que la sociedad barroca intentó controlar a través de la beneficencia. Incluso hubo propuestas para su encierro piadoso en determinados lugares: hospitales y hospicios.

El cuidado de la salud en los siglos XVI y XVII dependía de la purga, la sangría y la evacuación de los humores malignos. Las prácticas médicas de prevención contra la peste $\mathrm{o}$ la lepra se basaban enteramente en la exclusión y el rechazo de los infectados, de ahí que los marginados fueran tratados del mismo modo (Vigarello, 2005:151). Esa depuración hipocrática del cuerpo anatómico se trasladó como metáfora al cuerpo social de ahí que el equilibrio social comportara exclusiones y purgas. Así se comprenden las inquietudes de Sancho por proteger su ínsula de la invasión de esa "gente baldía y perezosa", una de las principales preocupaciones sociales del reino en los años en que El Quijote fue escrito. 
Respecto a los roles reservados a quienes nacían mujer, ya fuera en una familia hidalga o plebeya - en esto era indiferente la suerte-, el analfabetismo de por vida casi estaba garantizado, salvo para aquéllas que se dedicaran al servicio de Dios. Si no había vocación religiosa, la sociedad barroca reservaba a la mujer tres cometidos: ordenar el trabajo doméstico, perpetuar el linaje y satisfacer los requerimientos sexuales del esposo. De ahí que el matrimonio fuera culturalmente impuesto como el principal fin vital para ellas. El casamiento de las mujeres en la España barroca podía acaecer en cualquier momento a partir de los once o doce años y casi siempre antes de los veinte, cuando el promedio en Inglaterra o Francia rondaba los veintiséis. La diferencia de edad entre los cónyuges solía ser importante, no menos de diez años entre ambos y a veces varias décadas. Así, por ejemplo, el pintor, escultor y ayuda de cámara de Olivares, Alonso Cano, casó con una niña de doce años, María Magdalena de Uceda, sobrina del pintor Juan de Uceda, cuando él sobrepasaba holgadamente la treintena.

Una vez casadas, la baja natalidad, cuya ratio pese a los tópicos se situaba entre los tres y cuatro hijos por mujer, con largos periodos intergenésicos, se combinaba con una elevada mortalidad, tanto infantil como de las madres parturientas. Esto propiciaba frecuentemente segundas y terceras nupcias entre los hombres, que en mujeres sólo se producían en el caso de aquellas doncellas que, por intereses económicos de la familia, fueron casadas con vetustos caballeros adinerados, de los que pronto enviudaban.

Dentro del matrimonio, la moralidad patriarcal era muchísimo más permisiva con ellos que con ellas. El adulterio, castigado legalmente con la lapidación de la adúltera, si era masculino se toleraba en gran medida. De ahí la proliferación de hijos naturales fuera del matrimonio. Ya Fernando el Católico hizo, en su momento, arzobispo de Zaragoza y regente de Aragón a su bastardo, y Juan de Austria, hijo ilegítimo de Carlos I, fue héroe triunfador en Lepanto. Pero en el caso de las esposas el adulterio podía acarrearles, legalmente, la muerte y la de su amante a manos del marido, siempre que hubiera un testigo y fueran sorprendidos in fraganti.

Los hijos ilegítimos fueron especialmente abundantes en el medio urbano por dos causas: de un lado, la moral urbanita era mucho más laxa y relajada en las costumbres, y por otro, debido al nacimiento y ejercicio en este medio del ideal masculino de seducción donjuanesca. Se conocen datos de un abandono cercano al veinte por ciento de los bebés bautizados en Valencia a finales de siglo, lo cual creaba un caldo de cultivo inmejorable para las futuras víctimas de la prostitución o la picaresca, aspirantes al clero tanto masculino como femenino y la leva real.

A Felipe IV, por ejemplo, se le cuentan una treintena de hijos bastardos con damas de toda clase y condición, aunque sólo reconoció a uno, Juan José de Austria — pacificador de Nápoles y Sicilia, virrey de Cataluña, Portugal y Flandes - , fruto de una relación adúltera con una actriz de moda en la época, Doña María Inés Calderón, apodada "La Calderona", la cual acabó sus días como abadesa del monasterio benedictino de san Juan Bautista, pues todas estas amantes, extinguido el fuego de la pasión real, eran obligadas a ingresar en algún convento porque "ningún otro varón debía tocarlas, tras el Rey".

La piadosa y católica España pretendida por el Estado imperial y la Iglesia Contrarreformada no era tal cosa. Prueba fehaciente de lo dicho es la ingente cantidad de referencias normativas, que atañen a la represión del apetito sexual, contenidas tanto en las leyes, reglamentos y cédulas reales, como en los catecismos, escritos morales y sermones de las autoridades eclesiásticas desde los púlpitos. La proliferación de estas regulaciones es un 
síntoma inequívoco de la relajación moral imperante que las autoridades civiles y religiosas trataban de atajar. No obstante, estas prescripciones oficiales estaban dirigidas más a las aglomeraciones urbanas que a las aldeas y municipios pequeños, donde instituciones como la barraganería - concubinato o amancebamiento de los sacerdotes - eran bien vistas o al menos toleradas por sus feligreses desde el medioevo.

A pesar del rigor moral oficial, salvo por breves periodos $(1623,1632$ y 1661) en que Felipe IV dictó pragmáticas contra las mancebías, más por aplacar y complacer al clero contrarreformista que por su - nulo - efecto práctico, el ejercicio público de la prostitución en la España barroca era moneda corriente y su regulación estatal y municipal constituyó una abundante fuente de ingresos para las arcas oficiales. Esa reglamentación no era una excentricidad española, en casi toda Europa se repetía el mismo tolerante modelo. Según informa Le Goff (2008: 144), en fechas tan tempranas como el año 1170, hay constancia en los registros de Notre-Dame de París de que el gremio de prostitutas de la ciudad financió una de las vidrieras de la Catedral.

La única discriminación impuesta a las mujeres que se dedicaban a ella fue la de vestir en la calle con media capa negra que las distinguiera de las mujeres honradas. La normativa municipal utilizaba una taxonomía completa del gremio, atendiendo al lugar donde ejercían y a su mayor o menor independencia, dividiéndolo por categorías precisas. El nivel más bajo lo constituían las "putas de encrucijada", o "cantoneras", que ejercían en la calle y recibían algún salario de las arcas de la villa. Después se encontraban aquellas que trabajaban bajo tutela de algún proxeneta o en un prostíbulo regido, como negocio legal, por una madre o un padre que las protegía y esquilmaba sus beneficios. Por último, estaban las de categoría superior o "tusonas" que recibían en su propio piso o en mancebías de lujo que eran frecuentadas por personajes adinerados y nobles de la corte.

Las casas de prostitución fueron autorizadas y reguladas en Ordenanzas donde se reglamentaba su limpieza y seguridad, llegando a oficializar la presencia física de la guardia municipal en su interior para encargarse del orden, procurando que las mujeres no fueran maltratadas por los clientes. Una vez al año se prescribía un examen médico de estas mujeres, y obligatoriamente debían pasar el viernes de cuaresma en una iglesia donde el párroco les hacía admoniciones por su pecaminosa conducta. Madrid contaba con más de ochenta prostíbulos a principio de siglo, situados entre las calles Huertas y Embajadores, en Valencia todo el barrio de la Malvarrosa era una inmensa casa de citas y Sevilla tenía censadas a tres mil prostitutas hacia 1650.

Por la novela cervantina deambulan en algún momento todos estos tipos sociales, tanto masculinos como femeninos, en un alarde analítico de la estatificación social, sin parangón en el resto de la literatura áurea.

\subsection{Desenlace}

El final del episodio de Sancho como gobernador de la ínsula de Barataria se precipita tras el aviso del duque, anunciándole la conjura contra su persona, noticia que Sancho traslada a don Quijote por medio de una carta que dicta a su amanuense:

Escribiome el duque mi señor el otro día, dándome aviso que habian entrado en esta ínsula ciertas espías para matarme, y hasta ahora yo no he descubierto otra que un cierto doctor que está en este lugar asalariado para matar a cuantos gobernadores aqui vinieren: llámase el doctor Pedro Recio y es natural de Tirteafuera, iporque vea vuesa merced qué nombre para no temer que he de morir a sus manos! Este tal doctor dice él mismo que él no cura las enfermedades cuando las 
hay, sino que las previene, para que no vengan; y las medecinas que usa son dieta y más dieta, hasta poner la persona en los huesos mondos, como si no fuese mayor mal la flaqueza que la calentura. Finalmente, él me va matando de hambre, y yo me voy muriendo de despecho, pues cuando pensé venir a este gobierno a comer caliente y a beber frio, y a recrear el cuerpo entre sábanas de holanda, sobre colchones de pluma, he venido a hacer penitencia, como si fuera un ermitaño, y como no la hago de mi voluntad, pienso que al cabo me ha de llevar el diablo (Cervantes, 2008: 943944).

Pese a la amenaza que el duque le anuncia, insiste Sancho en la hambruna que el doctor le causa, y lo coloca a la altura de los espías que intentan finarlo, concluyendo con una declaración sucinta de su propia honradez: "hasta agora no he tocado derecho ni llevado cohecho", es decir, no privé a nadie de sus derechos sin motivo ni traté de enriquecerme aprovechando el cargo. Al contrario, Sancho dictó ordenanzas que mejorasen la vida de sus vasallos insulanos, ordenando "que no hubiese regatones de los bastimentos en la república" y que se declarasen los aditamentos del vino que se vendía y su lugar de procedencia, de modo que el precio se fijara "según su estimación, bondad y fama, y el que lo aguase o le mudase el nombre, perdiese la vida por ello". Moderó los precios del calzado "que corría con exorbitancia", impuso una tasa a los salarios de los criados, estableció durísimas penas a los que "cantasen cantares lascivos", prohibió el relato de milagros si no se tenían pruebas de ellos "por parecerle que los más que los ciegos cantan son fingidos" y finalmente "hizo y creó un alguacil de pobres, no para que los persiguiese, sino para que los examinase si lo eran". En definitiva, promulgó medidas bienhechoras y sensatas que "hasta hoy se guardan en aquel lugar, y que se nombran como Las constituciones del gran gobernador Sancho Panza" (Cervantes, 2008: 946).

A pesar de todo, sus depravados anfitriones no cejando en la intentona de reír a costa de sus desgracias, consumaron hasta el final sus maquinaciones simulando el ataque de los enemigos anunciados. Los criados, so pretexto de querer protegerlo, embuten el cuerpo del gobernador entre dos tablones, a modo de armadura, para que, en verdad, sin percatarse de quien lo hacía, lo vapulearan a gusto, aporreando los tablones y saltando sobre él hasta dejarlo baldado a golpes. Tras lo cual, Sancho se rinde y anuncia su abandono de la magistratura:

Abrid camino, señores míos, y dejadme volver a mi antigua libertad: dejadme que vaya a buscar la vida pasada, para que me resucite de esta muerte presente [...] Vuestras mercedes queden con Dios, y digan al duque, mi señor, que, desnudo nací, denudo me hallo: ni pierdo ni gano; quiero decir, que sin blanca entré en este gobierno, y sin ella salgo, bien al revés de como suelen salir los gobernadores de otras insulas (Cervantes, 2008: 957).

Sancho se despide así del oficio de gobernador, solicitando el regreso a su pasada "libertad", renegando del médico y de los porrazos que el cargo le habían propiciado, pero sabiéndose honrado, ya que abandonaba el gobierno de Barataria tal y como entró, sin blanca: "cuanto más que saliendo yo desnudo, como salgo, no es menester otra señal para dar a entender que he gobernado como un ángel." 


\section{CONCLUSIONES}

La moraleja final del episodio es benigna con el escudero a la vez que, implacable, critica la actitud de los nobles bromistas, que por entretener su señorial aburrimiento y desgana no dudan en zaherir a los dos famosos protagonistas de la genial novela cervantina. Tanto en la aventura voladora del gigante Malambruno, como en la del gobierno de Barataria, y otras más que giran en torno a los duques, cabría preguntarse, quiénes son los engañadores y quiénes los engañados; ¿los que, creyéndose superiores, demuestran una ínfima catadura moral, o los presuntos inferiores que aún engañados actúan noblemente?, ¿quién se traiciona más? Los aventureros se ven en un entorno que ellos consideran real y actúan con valentía y nobleza, mientras que sus burladores se saben en un contexto engañoso y a sabiendas actúan con cobardía y vileza contra los desvalidos crédulos, quedando en evidencia su bajeza moral y total falta de piedad cristiana.

Sancho, el labrador inculto y simplón, demuestra que su juicio sereno, combinado con los saberes populares extraídos del inmenso acervo hispano de refranes - que entonces se consideraban como los evangelios pequeños - atesorados en su memoria, fueron suficiente bagaje para el buen gobierno de la ínsula. En cambio, los duques y sus secuaces, pese a su noble estirpe, quedan retratados como viles y depravados burladores, que no dudan en hacer mofa de la buena voluntad, honradez y natural candidez de los célebres peregrinos manchegos. Para compensar tanta zafiedad de alta alcurnia, ganará protagonismo su contraparte, el tipo social del pícaro y su secuela en la novela picaresca inaugurada por el Lazarillo de Tormes en 1554. Aunque el gobierno sanchesco aparece como una cesión graciosamente otorgada por la élite para burla y escarnio del escudero, en el fondo del relato subyace la idea de que el pueblo llano, con un poco de sentido común y basándose en la experiencia colectiva acumulada, es tanto o más apto para el gobierno que la nobleza, sentimiento que se expresó con contundencia en las múltiples rebeliones que jalonaron el siglo XVII hispano.

\section{BIBLIOGRAFÍA}

Cervantes Saavedra, M. de (2008) Don Quijote de la Mancha. Madrid: Edición de Francisco Rico Santillana.

Fernández Ramos, J. C. (2017) Leviathan y la Cueva de la Nada: Hobbes y Gracián a la luz de sus metáforas. Barcelona: Anthropos.

Fernández Ramos, J. C. (2015) “Apuntes para una epistemología del análisis sociometafórico”, Ariadna histórica. Lenguajes, conceptos, metáforas, 4: 11-64 http://www.ehu.eus/ojs/index.php/Ariadna/ article/view/13068 [consulta 25/04/2018]

González García, J. M. (2006) La diosa Fortuna. Metamorfosis de una metáfora politica. Madrid: Antonio Machado Libros.

González García, J. M. (1998) Metáforas del Poder. Madrid: Alianza.

Hobbes, T. (2003) Leviatán: materia, forma y poder de un Estado eclesiástico y Civil. Buenos Aires: Editorial Losada.

Foucault, M. (1984) Las Palabras y las Cosas. Madrid: Siglo XXI.

Fox Keller, E. (1991) Reflexiones sobre género y ciencia. Valencia: Edicions Alfons el Magnànim.

Johnson, M. (1987) The Body on the Mind. Chicago: University of Chicago Press.

Kittay Feder, E. (1987) Metaphor: Its Cognitive Force and Linguistic Structure. Oxford: Oxford University Press.

Kofman, S. (1983) Nietzsche et la Métaphore. Paris: Éditions Galilée. 
Lakoff, G. y Johnson, M. (1981) Metaphors we live by. Chicago: University of Chicago Press.

Lizcano Fernández, E. (2006) Las Metáforas que nos piensan. Madrid: Ed. Bajo Cero/Traficantes de Sueños.

Lizcano Fernández, E. (1999) "La metáfora como analizador social”, Empiria, 2: 29-60, http://revistas.uned.es/index.php/empiria/article/view/709 [consulta 04/05/2018].

Merola, J. (1587) República original sacada del cuerpo humano. Barcelona: Pedro Malo, accesible en http://alfama.sim.ucm.es/dioscorides/consulta_libro.asp?ref $=X 533766051 \&$ idioma $=0 \quad$ [consulta $11 / 05 / 2018]$

Oliván, A. (1600) De Jure Fisci, (LXIII, 15), en H. Kramer (1984) Una sociedad conflictiva: España, 1469-1714. Madrid : Alianza, p. 318.

Peyne, S. G. (1985) La España Imperial. Madrid: Playor.

Redondo, A. (1992) Le corps comme métaphore dans l'Espagne des XVI et XVII siècles. Paris: Publications de la Sorbonne.

Santos Herrán, J. A. y Santos López, M. (2008) Quevedo, Saavedra Fajardo, Antonio Pérez y otros. El arte de gobernar. Antología de textos filosófico-políticos. Siglos XVI-XVII. Barcelona: Anthropos.

Shaw Fairman, P. (1981) España vista por los ingleses del siglo XVII. Madrid: Sociedad General Española de Librería.

Turner, B. S. (1996) Body and Society: explorations in social theory. Londres: Sage.

Ubieto et al. (1991) Introducción a la Historia de España. Barcelona: Teide.

Vigarello, G. (2005) Historia del Cuerpo. Madrid: Taurus-Santillana.

\section{Breve currículo:}

\section{José Carlos Fernández Ramos}

Licenciado (premio extraordinario curso 2001-2002) y doctor en Sociología (cum laude en 2012) por la UNED. Publica regularmente en revistas académicas digitales: Ariadna. Conceptos y Metáforas; Conceptos: Revista de Investigación Graciana; Intersticios. Revista Sociológica de Pensamiento Crítico (UCM); Empiria. Revista de Metodología de las CC. SS.; Imaginación o Barbarie, Boletín mensual de la RIIR. Autor de Leviathan y la Cueva de la Nada: Hobbes y Gracián a la luz de sus metáforas, Editorial Anthropos, 2017, Barcelona. Y coautor de Tan Lejos, Tan Cerca: Miradas contemporáneas entre España y América Latina, Editorial Tirant Humanidades, 2018, Valencia. 